UDC 621.791.042

Author: BOLDYREV Alexander Mikhaylovich, Doctor of Science in Engineering, Corresponding Member of Russia Academy of Architecture and Construction Science, Professor of Department of Metal Structures and Weld in Building Construction (Voronezh state technical University (VSTU)); Moskovsky prospect, 14, Voronezh, Russia, 394006, boldyreff@inbox.ru;

Author: ORLOV Alexander Semenovich, Doctor of Science in Engineering, Professor of Department of Metal Structures and Weld in Building Construction (Voronezh state technical University (VSTU)), Moskovsky prospect, 14, Voronezh, Russia, 394006, alex@mk.vrn.ru;

Author: GUSCHIN Dmitry Alexandrovich, PhD student of Voronezh state technical University (VSTU); Russia, 394006, Voronezh, Moskovsky prospect, 14; Engineer of Department of Public Company TSNIIS NITS MOSTY Scientific and Research Institute of Transport Construction (Public Company TSNIITS); Volgogradskaya str., 39b, Voronezh, Russia, 394028, dag55@mail.ru

\title{
NEW TECHNOLOGY FOR PRODUCTION OF GRANULAR ADDING MATERIAL WITH NANOMODIFYING ADDITIVES FOR STEEL ARC WELDING
}

\section{EXTENDED Abstract:}

The chemical analysis of metal seam showed that introduction of titanium dioxide with MCA intensifies transition of $\mathrm{Al}_{2} \mathrm{O}_{3}$ from slag into metal pool and provides double concentration of titanium in the seam compared to the one which appears in the interaction of bathtub with melted flux $\mathrm{AH}-47$ without $\mathrm{TiO}_{2}$ additives. The presence of oxides of titanium and aluminium of endogenous origin in the melt leads to formation of refractory particles with the center of $\mathrm{TiO}_{2}$ and $\mathrm{Al}_{2} \mathrm{O}_{3}$ in it. These particles are the centers of crystallization in the tail part of the molten pool and they remain in seam metal in the form of evenly distributed fine nonmetallic inclusions, which have crystallographic affinity with a matrix ( $\alpha$-iron). That provides the fine-grained seam structure with the raised and stable strength characteristics. This article compares the existing and developed technologies for production of MCA. The granulometric analysis of the powder $\mathrm{TiO}_{2}$ has demonstrated that when MCA is processed in the planetary mill, particles of titanium dioxide are crushed to a nanodimensional order. It is shown that the preparation of MCA in high-energy planetary mill (due to double increase of durability in coupling of the modifier with granulate) provides its stable structure, increases the cold resistance (20-25\%) and stability of strength characteristics 
along the length of welded seam. Metalgraphic researches determined that the fine-grained structure which linear size of grain is twice smaller than the one obtained in the old technology welding is formed in a seam. However the direct introduction of nanomodifiers in a molten pool through the flux or an electrode wire is not efficient because of their deactivation and high temperature in welding zone. Therefore it was offered to use modifiers in the mix with the cooling macroparticles in case of automatic welding of a bridge metalware under flux using metalchemical additive (MCA). The MCA consists of a chopped welding wire (granulate), the powdering modifying chemical additive $\mathrm{TiO}_{2}$ in the mixer with the displaced rotation axis "piyanay bochka" accorfint to the existing technology. However this MCA's technology doesn't provide the stable durability of modifier's coupling with the granulate's surface and it is not able to control its structure under production conditions that, certainly, negatively affects on stability of welded connections' properties. Therefore one of the main task in this research was to improve the existing technology to increase durability of the modifier' coupling with granulate. Welding is one of the main technological methods to connect details and nodes in production process. However $70-80 \%$ of metalware destruction occuring in operational process are related to welded connections. These destructions are mainly fragile. The increased firmness of welded connections against the fragile destruction is needed due to development of northern and east regions in Russia. The most perspective method to increase cold resistance of welded connections is the crush of seam metal grain by means of nanomodification.

Keywords: welding, fragile destruction, modification of nanoparticles.

MACHINE-READABLE INFORMATION ON CC-LICENSES (HTML-CODE) IN METADATA OF THE PAPER

$<$ a rel="license" href="http://creativecommons.org/licenses/by/4.0/" ><img alt="Creative Commons License" style="borderwidth:0" src="https://i.creativecommons.org/l/by/4.0/88x31.png" $/></ \mathrm{a}><$ br $/><$ span xmlns:dct="http://purl.org/dc/ terms/" href="http://purl.org/dc/dcmitype/Text" property="dct:title" rel="dct:type" $>$ New technology for production of granular adding material with nanomodifying additives for steel arc welding $</$ span $>$ by $<$ a xmlns:cc="http://creativecommons. $\mathrm{org} / \mathrm{ns} \#$ " href="Nanotehnologii v stroitel'stve = Nanotechnologies in Construction. 2016, Vol. 8, no.6, pp. 124-143. DOI: dx.doi.org/10.15828/2075-8545-2016-8-6-124-143" property="cc:attributionName" rel="cc:attributionURL">Boldyre v A.M., Orlov A.S., Guschin D.A. </a > is licensed under a <a rel="license" href="http://creativecommons.org/licenses/ by $/ 4.0 / ">$ Creative Commons Attribution 4.0 International License $</ \mathrm{a}>$. $<$ br $/>$ Based on a work at $<$ a xmlns:dct="http:// purl.org/dc/terms/" href=" http://nanobuild.ru/en_EN/nanobuild-6-2016/" rel="dct:source"> http://nanobuild.ru/ en_EN/nanobuild-6-2016/</a $>$. $<$ br $/>$ Permissions beyond the scope of this license may be available at $<$ a xmlns:cc $="$ http: $/ /$ creativecommons.org/ns\#" href="dag55@mail.ru"rel="cc:morePermissions" $>$ dag55@mail.ru $</ \mathrm{a}>$. 


\section{References:}

1. Paton B.E. Sovremennyie napravleniya issledovaniy i razrabotok v oblasti svarki i prochnosti konstruktsiy [Modern research and development in welding and structure strength]. Avtomaticheskaya svarka [Automatic welding]. 2003. №10/11, pp. 7-13. (In Russian).

2. Lyubovits $G$. Razrushenie: v 6 tomah [Destruction: 6 volumes. Volume 1]. Moscow: Mir, 1973. 616 p. (In Russian).

3. Eremin K.I. Reestr zdaniy i sooruzheniy 2007-2010 g.g. [The list of the buildings and structires 2007-2010] Moscow, 2011. 320 p. (In Russian).

4. Paton B.E. Sovremennyie napravleniya povyisheniya prochnosti i resursa svarnyih konstruktsiy [Modern ways to increase strength of welded structures]. Avtomaticheskaya svarka [Automatic welding]. 2000. №9/10, pp. 3-9. (In Russian).

5. Nott Dzh. F. Osnovyi mehaniki razrusheniya [The principles of destruction mechanics. Edited by V.G. Kudryashova]. Moscow, Metallurgiya, 1978. 256 p. (In Russian).

6. Ioffe A.F. Deformatsiya i prochnost kristallov [Deformation and strength of crystals] / A.F. Ioffe, M.V. Kirpicheva, N.A. Levitskaya. Zhurnal Russkogo fizikohimicheskogo obschestva [The journal of Russian physical and chemical society]. 1924. V. 56, pp. 1489-1495. (In Russian).

7. Petch N. Metallograficheskie aspektyi razrusheniya / N. Petch // [Destruction: 6 volumes. Volume 1]. Mikroskopicheskie i makroskopicheskie osnovyi mehaniki razrusheniya [Microscopic and macroscopic bases of mechanics of destruction]. Moscow, Mir, 1973. 616 p. (In Russian).

8. Alov A.A., Bobrov G.B. Modifitsirovanie metalla shva pri svarke alyuminiya [Modification of the metal seam in aluminium welding]. Svarochnoe proizvodstvo [Welding production]. 1959. №6. p.1-6. (In Russian).

9. Hrenov K.K. Osobennosti modifitsirovaniya titanom svarnyih shvov pri avtomaticheskoy svarke sredneuglerodistyih staley / K.K. Hrenov, L.A. Pozdnyak, Yu.A. Yuzvenko, M.S. Samotryasov // Svarochnoe proizvodstvo [Welding production]. 1959, №6. pp. 6-8. (In Russian).

10. Boldyirev A.M., Antonov E.G., Dorofeev E.B. Upravlenie kristallizatsiey metalla pri svarke plavleniem [Control of metal crystallization in fuse welding]. Svarochnoe proizvodstvo [Welding production]. 1974. № 6. pp 35-37. (In Russian).

11. Kobernik N.V., Miheev R.S., Pankratov A.S., Linnik A.A. Sovremennye predstavleniya o modificirovanii naplavlennogo metalla i metalla shva nanorazmernymi chasticami (obzor) [Modern conceptions on the modification of weld metal and 
seam metal with nanosize particles (review)]. Svarka i Diagnostika [Weld and Diagnostics]. 2015. № 5. pp. 13-18. (In Russian).

12. Boldyirev A.M., Guschin D.A., Kuznetsov V.D., Smirnov I.V. Otsenka termodinamicheskih faktorov vzaimodeystviya metallohimicheskoy prisadki so svarochnoy vannoy [Evaluation of thermodynamical factors of interaction between additive and molten metal] Nauchnyiy vestnik Voronezhskogo GASU. Stroitelstvo i arhitektura. Voronezh: 2014. Issue. № 2 (34), pp. 24-33. (In Russian).

13. Boldyirev A.M., Golovko V.V., Guschin D.A., Fomichev S.K., Kuznetsov V.D., Smirnov I.V. Osobennosti raspredeleniya i rol nemetalicheskih vklyucheniy v metalle shva pri vvedenii v svarochnuyu vannu nano oksidov [The characteristics of distribution and role of non-metal inclusions in seam metal when nanooxides are introduced into molten metal]. Svarka i Diagnostika [Weld and Diagnostics]. Moscow, 2015. № 6. pp. 25-28. (In Russian).

14. Kuznetsov V.D., Stepanov D.V. Struktura i svoystva metalla svarnogo shva, modifitsirovannogo nanooksidami [The structure and properties of the metal in seam modified with nanooxides]. Avtomaticheskaya svarka [Automatic welding]. 2015. № 11. pp. 19-24. (In Russian).

15. Boldyirev A.M., Grigorash V.V. Problems of micro- and nanomodified joints under building metal structure welding. Nanotechnologies in Construction. 2011. Vol. 3, N 3. pp. 42-52. URL: http://nanobuild.ru/ru_RU/journal/Nanobuild_3_2011_ RUS.pdf (Date of access: 22.11.2016). (In Russian).

16. Sposob elektrodugovoy svarki [The method of electric arc welding]: inventor's certificate USSR № 584996 :B 23 K 9/00. / A.M. Boldyirev, E.B. Dorofeev, A.S. Petrov i T.I. Glazeva (SSSR). № 2361777/25-027; appl. 17.04.76; published. 25.12.77. Bul. № 47. 2 p. (In Russian).

17. Boldyirev A.M., Grebenchuk V.G., Guschin D.A. Vliyanie dioksida titana v sostave metallohimicheskoy prisadki na mehanicheskie svoystva metalla shva stali 10HSND [Influence of titanium dioxide in the metal and chemical additive on the mechanical properties of seam metal of steel 10HSND]. Svarka i Diagnostika [Weld and Diagnostics]. Moscow, 2014. № 3. pp. 39-42. (In Russian).

18. Boldyirev A.M., Grigorash V.V., Guschin D.A., Grebenchuk V.G. Issledovanie prochnosti stsepleniya chastits $\mathrm{v}$ modifitsiruyuschey prisadke dlya svarki mostovyih konstruktsiy pod flyusom [The study of particles adhesive strength in modifying agent for bridge structure welding]. Nanotehnologii v stroitelstve [Nanotechnologies in Construction]. 2012. Vol. 4, № 2. pp. 56-69. URL: http://nanobuild.ru/ ru_RU/journal/Nanobuild_2_2012_RUS.pdf (Date of access: 22.11.2016) (In Russian). 
19. Sposob polucheniya granulirovannogo prisadochnogo materiala dlya dugovoy svarki [The method to produce granular additive material for electric arc welding]: patent 2574930 Russian Federation : MPK8 V23K 35/40, B22F 1/02, B22F 9/04, B02C 17/08 / Boldyirev A.M., Guschin D.A., Grebenchuk I.V., zayavitel i patentoobladatel Federalnoe gosudarstvennoe byudzhetnoe obrazovatelnoe uchrezhdenie vyisshego professionalnogo obrazovaniya «Voronezhskiy gosudarstvennyiy arhitekturno-stroitelnyiy universitet». - 2014119083/02, zayavl. 12.05.2014, published. 10.02.2016, Bul. № 4. - 4 p. (In Russian).

20. Guschin D.A., Boldyirev A.M., Grebenchuk V.G., Tkachev A.G., Blinov S.V. Poluchenie metallohimicheskoy svarochnoy prisadki s nanodispersnyimi chastitsami dioksida titana [Production of metal chemical welding additive with nanodispersed particles of titanium dioxide]. Nanotehnologii v stroitelstve [Nanotechnologies in Construction]. 2013. Vol. 5, N 6. pp. 53-66. URL: http://nanobuild.ru/ru_RU/ journal/Nanobuild_6_2013_RUS.pdf (Date of access: 22.11.2016) (In Russian).

21. Saltyikov S.A. Stereometricheskaya metallografiya [Stereometrical metallographics]. Moscow, Metallurgiya, 1976. 270 p. (In Russian).

22. Newhouse D.L. Relationships Between Charpy Impact Energy, Fracture Appearance and Test Temperature in Alloy Steels / D.L. Newhouse. WELDING RESEARCH SUPPLEMENT. 1963. № 3. p. 105-114.

23. Goritskiy V.M. Otsenka soprotivleniya rasprostraneniya treschinyi po rezultatam ispyitaniy na udarnuyu vyazkost [Evaluation of crack spreading resistance in the tests on impact elasticity]. Zavodskaya laboratoriya [Factory laboratory]. 1984. №7. pp. 70-73. (In Russian).

24. Golovko V.V. Vliyanie nemetallicheskih vklyucheniy na formirovanie strukturyi metalla svarnyih shvov vyisokoprochnyih nizkolegirovannyih staley [The influence of non-metal inclusions on the formation of structure of weld seam metal in high-strength low-alloy steel]. Avtomaticheskaya svarka [Automatic welding]. 2013. № 6. pp. 3-11. (In Russian).

DeAr COlleagues!

THE REFERENCE TO THIS PAPER HAS THE FOLLOWING CITATION FORMAT:

Boldyrev A.M., Orlov A.S., Guschin D.A. New technology for production of granular adding material with nanomodifying additives for steel arc welding. Nanotehnologii v stroitel'stve = Nanotechnologies in Construction. 2016, Vol. 8, no.6, pp. 124143. DOI: dx.doi.org/10.15828/2075-8545-2016-8-6-124-143. (In Russian). 
Автор: БОЛДЫРЕВ Александр Михайлович, д-р техн. наук, чл.-кор. РААСН, профессор кафедры «Металлических конструкций и сварки в строительстве», Воронежский государственный технический университет (ВГТУ); Московский проспект, д. 14, г. Воронеж, Воронежская область, Россия, 394026, boldyreff@inbox.ru;

Автор: ОРЛОВ Александр Семёнович, д-р техн. наук, профессор, заведующий кафедрой «Металлические конструкции и сварка в строительстве», Воронежский государственный технический университет (ВГТУ); Московский проспект, д. 14, г. Воронеж, Воронежская область, Россия, 394026, alex@mk.vrn.ru;

Автор: ГУЩИН Дмитрий Александрович, аспирант кафедры «Металлических конструкций и сварки в строительстве», Воронежский государственный технический университет (ВГТУ); Московский проспект, д. 14, г. Воронеж, Воронежская область, Россия, 394026; инженер филиала Научно-исследовательского института транспортного строительства (ОАО ЦНИИС) «Научноисследовательского центра «Мосты» («НИЦ «Мосты»); ул. Волгоградская д.39б, г. Воронеж, Россия, 394028, dag55@mail.ru

\section{НОВАЯ ТЕХНОЛОГИЯ ПОЛУЧЕНИЯ ГРАНУЛИРОВАННОГО ПРИСАДОЧНОГО МАТЕРИАЛА С НАНОМОДИФИЦИРУЮЩИМИ ДОБАВКАМИ ДЛЯ ДУГОВОЙ СВАРКИ СТАЛЕЙ}

АННОТАЦИЯ К СТАТЬЕ (АВТОРСКОЕ РЕЗЮМЕ, РЕФЕРАТ):

Сварка является одним из основных технологических способов соединения деталей и узлов при их изготовлении. Однако 70-80\% разрушений металлоконструкций в процессе эксплуатации связано со сварными соединениями. Эти разрушения преимущественно хрупкие. Повышение стойкости сварных соединений против хрупкого разрушения актуально в связи с освоением северных и восточных регионов России. Самым перспективным способом повышения хладостойкости сварных соединений является измельчение зерна металла шва с помощью наномодифицирования. Однако введение наномодификаторов непосредственно в сварочную ванну через флюс или электродную проволоку не эффективно из-за их дезактивации и высокой температуры в зоне сварки. Поэтому было предложено применять модификаторы в смеси с охлаждающими макрочастицами при автоматической сварке под флюсом мостовых металлоконструкций с применением металлохимической присадки (МХП). МХП состоит из рубленой сварочной проволоки (гранулята), опудренной модифицирующей химической добавкой $\mathrm{TiO}_{2}$ в смесителе со смещенной осью вращения «пьяная бочка» по существующей технологии. Однако эта технология получения МХП не обеспечивает стабильной 
прочности сцепления модификатора с поверхностью гранулята и не имеет возможности контролировать её состав в производственных условиях, что, безусловно, отрицательно отражается на стабильности свойств сварных соединений. Поэтому одной из главных задач работы была модернизация существующей технологии с целью повышения прочности сцепления модификатора с гранулятом. В статье дано сравнение существующей и разработанной технологии изготовления МХП. Гранулометрический анализ порошка $\mathrm{TiO}_{2}$ показал, что при обработке МХП в планетарной мельнице происходит измельчение частиц диоксида титана до наноразмерного порядка. Показано, что приготовление МХП в высокоэнергетической планетарной мельнице (за счёт двухкратного повышения прочности сцепления модификатора с гранулятом) обеспечивает стабильный её состав, повышает хладостойкость (на 20-25\% ) и стабильность прочностных характеристик по длине сварного шва. В результате металлографических исследований установлено, что в шве формируется мелкозернистая структура с линейным размером зерна в 2 раза меньшим, чем при сварке по старой технологии. По результатам химического анализа металла шва установлено, что введение диоксида титана с МХП интенсифицирует переход $\mathrm{Al}_{2} \mathrm{O}_{3}$ из шлака в сварочную ванну и обеспечивает концентрацию титана в шве в 2 раза большую, чем при взаимодействии ванны с расплавленным флюсом АН-47 без добавок $\mathrm{TiO}_{2}$. Наличие в расплаве оксидов титана и алюминия эндогенного происхождения приводит к образованию в расплаве тугоплавких частиц с центром из $\mathrm{TiO}_{2} \mathrm{Al}_{2} \mathrm{O}_{3}$. Эти частицы являются центрами кристаллизации в хвостовой части ванны и остаются в металле шва в виде равномерно распределенных мелкодисперсных неметаллических включений, имеющих кристаллографическое сродство с матрицей ( $\alpha$-железа), что обеспечивает получение мелкозернистой структуры шва с повышенными и стабильными прочностными характеристиками.

Ключевые слова: сварка, хрупкое разрушение, наномодифицирование.

DOI: dx.doi.org/10.15828/2075-8545-2016-8-6-124-143

\footnotetext{
МАШИНОЧИТАЕМАЯ ИНФОРМАЦИЯ О СС-ЛИЦЕНЗИИ В МЕТАДАННЫХ СТАТЬИ (НTML-КОД):

$<$ a rel="license" href="http://creativecommons.org/licenses/by/4.0/"><img alt="Лицензия Creative Commons" style="borderwidth:0" src="https://i.creativecommons.org/l/by/4.0/88x31.png" / ></a $><$ br / $>$ Произведение "<span xmlns:dct="http:// purl.org/dc/terms/" href="http://purl.org/dc/dcmitype/Text" property="dct:title" rel="dct:type"> Новая технология получения гранулированного присадочного материала с наномодифицирующими добавками для дуговой сварки сталей </span $>$ " созданное автором по имени <a xmlns:cc="http://creativecommons.org/ns\#" href="Нанотехнологии в строительстве. - 2016. - Tом 8,№ 6. - C. 124-143. - DOI: dx.doi.org/10.15828/2075-8545-2016-8-6-124-143 " property="cc:attributionName" rel="c c:attributionURL">Болдырев A.M., Орлов А.С., Гущин Д.А. </a>, публикуется на условиях <a rel="license" href="http:// creativecommons.org/licenses/by/4.0/"> лицензии Creative Commons «Attribution» ( «Атрибуция») 4.0 Всемирная $<$ / a $>$. $<$ br / > Основано на произведении c $<$ a xmlns:dct="http://purl.org/dc/terms/" href="http://nanobuild.ru/ru_RU/ nanobuild-6-2016/" rel="dct:source">http://nanobuild.ru/ru_RU/nanobuild-6-2016/</a $>$.<br />Разрешения, выходящие за рамки данной лицензии, могут быть доступны на странице <a xmlns:cc="http://creativecommons.org/ns\#" href="dag55@ mail.ru" rel="cc:morePermissions" $>$ dag55@mail.ru</a $>$.
} 
варные конструкции широко применяются в строительстве, транспорте, судостроении, энергетике и других отраслях промышленности. Объёмы производства сварных конструкций во всём мире составляют сотни миллионов тонн. При этом, как отметил академик Б.Е. Патон, основным материалом по-прежнему остается сталь. До 70\% мирового потребления металлопроката приходится на производство металлоконструкций и сооружений с помощью сварки [1]. Сварка как технологический процесс занимала ведущее место в производстве металлических конструкций на протяжении всего ХХ столетия и, по-видимому, в будущем сохранит своё главенствующее положение во всех отраслях промышленного производства. Технологичность изготовления и высокая пространственная прочность конструкций обеспечили широкое применение автоматической сварки под флюсом и в смеси защитных газов при изготовлении и монтаже трубопроводов, мостовых конструкций и решётчатых перекрытий в крупнопролётных зданиях. Однако на протяжении прошлого столетия произошло большое количество катастроф во время эксплуатации металлоконструкций с разрушениями и нередко с человеческими жертвами. В течение второй половины XIX и первой четверти XX веков в США и Европейских странах было зарегистрировано огромное количество разрушений, связанных с мостовыми конструкциями, нефтепроводами, газгольдерами, водопроводными магистралями, резервуарами и другими подобными конструкциями и сооружениями, находившимися в эксплуатации [2]. Не миновали эти случаи и нынешнее время. Согласно статистике, за 2001-2010 гг. в мире произошло более 1500 разрушений в решётчатых перекрытиях современных общественных зданий (гипермаркетов, стадионов, катков и т.п.) [3]. Причём 70-80\% отказов металлических конструкций связано со сварными соединениями и металлом шва, хотя его массовая доля в конструкции редко превышает 1\% [4]. Исследования случаев отказа крупных металлоконструкций показали, что большинство разрушений носило хрупкий характер, происходило без заметных предшествующих деформаций. 
Рассмотрение причин и вероятности появления подобных разрушений твёрдых тел и, в частности, металлических стало объектом исследования механики разрушения [5]. Многочисленные статические и ударные испытания на разрыв надрезанных пластин выявили увеличение хрупкости металлических тел при снижении температуры. При нормальной (комнатной) температуре разрушение испытуемых образцов сопровождалось пластическими деформациями в зоне разрыва. С понижением температуры величина пластической деформации уменьшалась, а при определенной критической температуре Ткр практически при нулевой деформации разрушение становилось хрупким.

А.Ф. Иоффе ещё в 1929 г., исходя из представлений о двух типах разрушения: разрушение вследствие среза - пластическое - и вследствие отрыва - хрупкое, впервые предложил, описал и объяснил схему перехода твёрдого тела в хрупкое состояние [6]. Согласно этой схеме принято, что сопротивление отрыву $\sigma_{\text {отр }}$ (хрупкая прочность) в основном определяется силами межатомного сцепления и мало зависит от температуры, а пластичность металла, характеризуемая пределом текучести $\sigma_{\mathrm{S}}$, связана с подвижностью дислокаций, и с понижением температуры круто возрастает, приближаясь к значениям хрупкой прочности (рис. 1). При $\mathrm{T}=\mathrm{T}_{\text {кр }}$ кривые $\sigma_{\mathrm{B}}=\mathrm{f}(\mathrm{T})$ и $\sigma_{\mathrm{S}}=\mathrm{f}(\mathrm{T})$ пересекаются, и вязкое разрушение сменяется хрупким. Уменьшение предела текучести с $\sigma_{\mathrm{S}}$ до $\sigma_{\mathrm{s}}{ }^{\prime}$, означающее снижение сопротивления движению дислокаций, повышает их подвижность и, как следствие, пластичность металла, а переход от вязкого к хрупкому разрушению отодвигается в сторону более низких температур (рис. 1).

Характер разрушения металлов тесно связан с их внутренней структурой. Металлы с объёмно-центрированной кубической $(\mathrm{Fe}, \mathrm{W}$, Mo) и гексагональной плотно-упакованной решетками ( $\mathrm{Zn}, \mathrm{Be})$ пластичны в диапазоне относительно высоких температур, но становятся хрупкими при низких температурах. А металлы с гранецентрированной кубической решеткой $(\mathrm{Al}, \mathrm{Cu}, \mathrm{Ni}$, в том числе и дорогостоящие аустенитные высоколегированные стали) проявляют пластичность даже при температурах, приближающихся к абсолютному нулю. Сварные металлоконструкции, изготавливаемые из малоуглеродистых сталей, которые имеют объёмно-центрированную кубическую решётку, при низких температурах проявляют склонность к хрупкому разрушению. Проблема повышения стойкости сварных соединений против хрупко- 


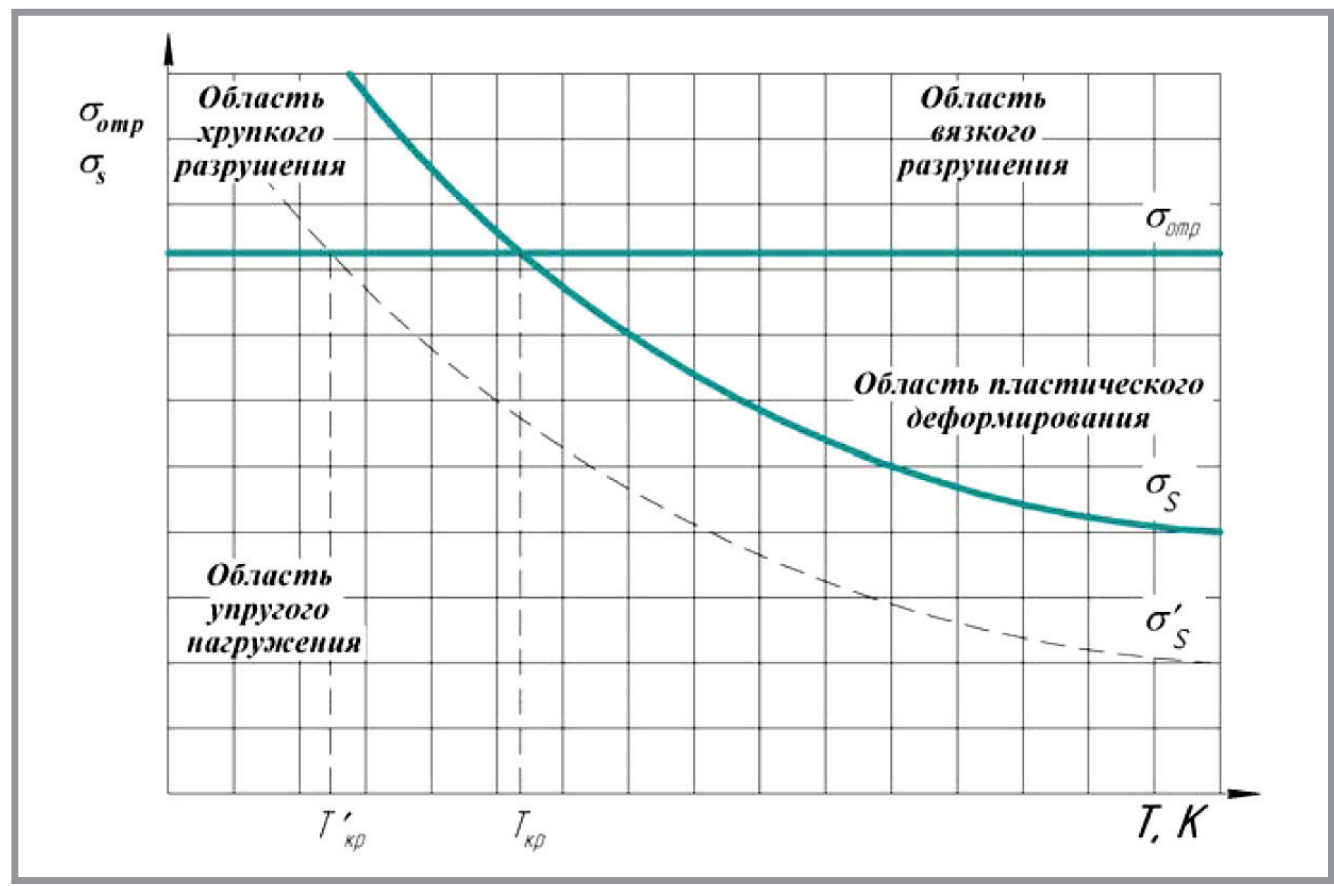

Рис. 1. Схема перехода твёрдого тела по А.Ф. Иоффе в хрупкое состояние при понижении температуры

го разрушения крупных металлоконструкций приобретает особую актуальность в связи с интенсификацией освоения северных и восточных регионов России. Поэтому повышение вязкости металла шва сварных соединений из малоуглеродистых низколегированных сталей сейчас приобретает особую значимость.

Анализ способов уменьшения вероятности хрупкого разрушения металлов показал, что единственныл средствол повышения пластичности леталла без существенного снижения его прочности является излельчение зерна, увеличивающее число полос скольжения при нагрузке [7]. В связи с этим, вопросам измельчения структуры металла швов уделяется постоянное внимание. Исследовано много способов измельчения зерна в металле шва при дуговой сварке: пульсация защитного газа, колебания дуги в пространстве, импульсно-дуговая сварка, введение в сварочную ванну ультразвуковых колебаний и др. [8-14]. Наиболее эффективным оказалось введение в сварочную ванну тугоплавких модификаторов, служащих центрами гетерогенной кристаллизации в хвостовой части ванны. Этот способ находит применение также и в комбинации с вышеуказанными способами. 
Как показала практика, введение модификаторов непосредственно в сварочную ванну через флюс или электродную проволоку менее эффективно, чем при литье, из-за высокой температуры в зоне сварки [15]. Поэтому было предложено применять модификаторы в смеси с охлаждающими макрочастицами (микрохолодильниками) [16].

В отечественном мостостроении в настоящее время стальные мосты изготавливают, в основном, из низкоуглеродистых сталей $10 \mathrm{XCHД}$ и $15 \mathrm{XСНД.} \mathrm{При} \mathrm{заводском} \mathrm{изготовлении} \mathrm{и} \mathrm{монтаже} \mathrm{элементов} \mathrm{кон-}$ струкции стыковые соединения толщиной 12-40 мм выполняют автоматической сваркой под флюсом с металлохимической присадкой (МХП), которая обеспечивает более высокий КПД дуги и улучшает структуру металла шва. МХП представляет собой смесь гранулята (проволочная крошка $\varnothing 2 \times 2$ мм - микрохолодильник) и модифицирующей химической добавки в виде порошка диоксида титана. Применяемая сегодня технология изготовления МХП - опудривание гранулята в низкоэнергетическом цилиндрическом смесителе со смещенной осью вращения (так называемая «пьяная бочка»), последующая прокалка, хранение перед сваркой в печи при температуре $80^{\circ} \mathrm{C}$ и транспортировка к месту сварки - из-за низкой прочности сцепления [17] и неконтролируемых потерь не гарантирует постоянства состава МХП. Кроме того, возможны потери $\mathrm{TiO}_{2}$ по длине шва в процессе засыпки МХП в стык, а, следовательно, и колебания прочностных свойств металла шва [18]. Нами была разработана новая технология изготовления МХП [19]. Вместо низкоэнергетического смесителя «пьяная бочка» с ускорением соударения смешиваемых частиц не более $1 \mathrm{~g}$ предложено увеличить на порядок энергию смешивания. Это, во-первых, позволило повысить прочность сцепления модифицирующих частиц с поверхностью гранулята [18], во-вторых, как показано ниже, изменить гранулометрический состав присадки.

Согласно теории механики разрушения концентрация напряжений около внутренних микродефектов кристаллического тела (микротрещины, дислокации, инородные включения и др.) прямо пропорциональна растягивающим напряжениям $\sigma$ и корню квадратному из линейного размера микродефекта $a$ [5]:

$$
K=\sigma \sqrt{\pi a} .
$$


Если $\mathrm{K}$, названный коэффициентом интенсивности напряжений, превысит критическую величину, этот дефект становится зародышем трещины, которая в результате слияния (коалесценции) с другими микродефектами развивается в магистральную трещину.

Отсюда следует, что чем меньше размеры модифицирующих частиц - центров кристаллизации и, как показали исследования, центров неметаллических включений в шве - тем меньше зерно металла шва, тем меньше размер а и коэффициент интенсивности напряжений.

В связи с этим, была проведена сравнительная оценка гранулометрического состава МХП, изготовленной по старой и новой технологиям. Для изготовления опытных партий МХП использовали планетарную мельницу Pulverisette 5, в которой центробежное ускорение барабанов может достигать $60 \mathrm{~g}$. Экспериментально было установлено, что при ускорении соударяемых частиц более $20 \mathrm{~g}$ модифицирующие частицы $\mathrm{TiO}_{2}$ измельчаются со 150 мкм до 1 мкм и менее (табл. 1). Кроме того, происходит дробление гранулята и его пластическая деформация.

Измельчение модификатора, деформация и дробление гранулята повышают удельную энергию соударяемых частиц и увеличивают вероятность химического взаимодействия между ними с образованием прочных связей. Наши исследования показали, что новая технология изготовления МХП в 2,7 раза повысила прочность сцепления модификатора с гранулятом.

Таблица 1

Результаты гранулометрического анализа модифицирующей добавки $\mathrm{TiO}_{2}$ при изготовлении МХП по новой и существующей технологиям

\begin{tabular}{|c|c|c|c|c|}
\hline \multirow{2}{*}{$\begin{array}{c}\text { Состояние } \\
\text { исследуемой добавки }\end{array}$} & \multicolumn{4}{|c|}{ Распределение частиц по размерам (\% ) } \\
\hline & $\begin{array}{c}\text { Менее } \\
\text { 0,5 мкм }\end{array}$ & 0,5-1,0 мкм & 1-3 мкм & 3-8 мкм \\
\hline В состоянии поставки & 16,0 & 25,0 & 58,0 & 1,0 \\
\hline $\begin{array}{l}\text { После обработки } \\
\text { в смесителе }\end{array}$ & 18,0 & 30,0 & 52,0 & - \\
\hline $\begin{array}{l}\text { После обработки } \\
\text { в планетарной } \\
\text { мельнице }\end{array}$ & 30,0 & 30,0 & 30,0 & 10,0 \\
\hline
\end{tabular}


При обработке МХП по новой технологии $60 \%$ частиц $\mathrm{TiO}_{2}$ имеют размер менее 1 мкм, а при обработке по старой технологии гранулометрический состав частиц почти не меняется.

Металлографические исследования показали, что при сварке с МХП, изготовленной по новой технологии, в шве формируется мелкозернистая структура с линейным размером зерна в 2 раза меньшим, чем при сварке по старой технологии (рис. 2).

Прочностные свойства металла швов (предел прочности $\sigma_{\text {в }}$, относительное удлинение $\delta$ и ударная вязкость KCU) определяли на стандартных образцах, по стандартным методикам. Стабильность этих свойств по длине шва оценивали коэффициентом стабильности, представляющим отношение величины разброса (разница между максимальным

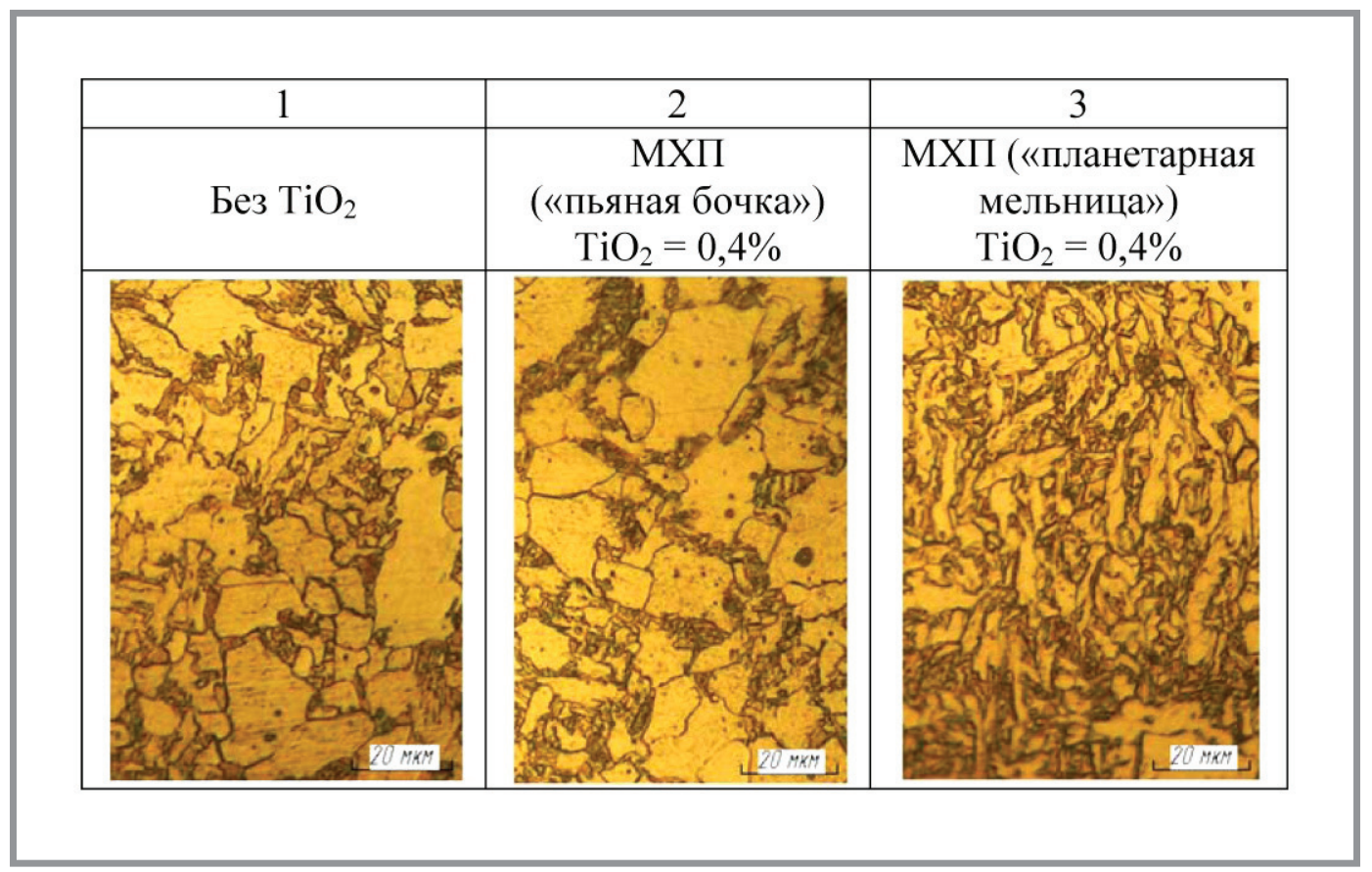

Рис. 2. Микроструктура металла корневого шва, выполненного с МХП, изготовленной по сравниваемым технологиям (увеличение х397):

1 - контрольный образец, сваренный с гранулятом без добавления $\mathrm{TiO}_{2}$ (средний размер зерна $\mathrm{d}_{\mathrm{cp}}=8 \mathrm{м \kappa м}$ );

2 - образец, сваренный с МХП, приготовленной по старой технологии $\left(\mathrm{d}_{\mathrm{cp}}=8 \mathrm{MKм}\right)$;

3 - образец, сваренный с МХП, приготовленной по новой технологии $\left(\mathrm{d}_{\mathrm{cp}}=4\right.$ мкм). Средний размер зерна определяли методом секущей [21] 
$\left(\mathrm{m}_{\max }\right)$ и минимальным $\left(\mathrm{m}_{\min }\right)$ к среднему $\left(\mathrm{m}_{\mathrm{cp}}\right)$ значению определяемого параметра m:

$$
k_{c m}=\frac{m_{\max }-m_{\min }}{m_{c p}} .
$$

Отсюда следует, что чем меньше коэффициент стабильности, тем стабильнее прочностные показатели металла шва. Результаты механических испытаний образцов из металла шва и коэффициентов стабильности представлены в табл. 2.

Данные свидетельствуют о том, что механические свойства металла всех испытанных швов удовлетворяют нормативным требованиям

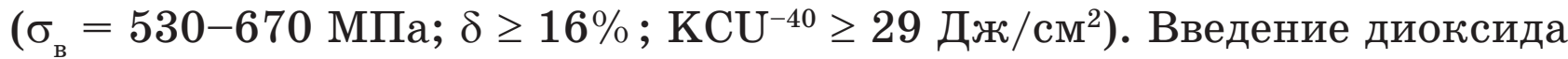
титана в гранулят положительно влияет на пластические свойства металла шва - повышается относительное удлинение и ударная вязкость. И, самое главное, при изготовлении МХП по новой технологии повышается стабильность этих свойств, особенно ударной вязкости - почти в 2,5 раза.

\section{Влияние технологии изготовления МХП на механические свойства металла шва}

\begin{tabular}{|c|c|c|c|c|c|c|}
\hline \multirow{2}{*}{$\begin{array}{c}\text { Варианты } \\
\text { приготовле- } \\
\text { ния МХПI }\end{array}$} & \multicolumn{4}{|c|}{ Испытания на статический разрыв } & \multicolumn{2}{|c|}{$\begin{array}{c}\text { Испытания } \\
\text { на ударный изгиб }\end{array}$} \\
\hline & $\begin{array}{c}\sigma_{\mathrm{s}}, \\
\text { МПа }\end{array}$ & $\mathbf{K} \sigma_{\text {в }}$ & $\delta, \%$ & K反 & 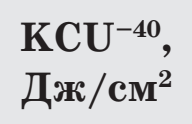 & $\mathrm{K}_{\mathrm{KCU}}{ }^{-40}$ \\
\hline $\begin{array}{l}\text { Гранулят } \\
\text { без } \mathrm{TiO}_{2}\end{array}$ & $\frac{625-546}{590}$ & 0,135 & $\frac{26-16}{20}$ & 0,510 & $\frac{86-56}{73}$ & 0,411 \\
\hline $\begin{array}{l}\text { Существу- } \\
\text { ющая техно- } \\
\text { логия }\end{array}$ & $\frac{610-572}{590,2}$ & 0,064 & $\frac{27-23}{25}$ & 0,160 & $\frac{92-72}{84,9}$ & 0,239 \\
\hline $\begin{array}{l}\text { Новая } \\
\text { технология }\end{array}$ & $\frac{592-568}{578}$ & 0,042 & $\frac{29-26}{27,3}$ & 0,110 & $\frac{115-104}{112,5}$ & 0,098 \\
\hline
\end{tabular}

В числителе даны максимальные и минимальные значения прочностных свойств:

- при статических испытаниях - по 3 гагаринским образцам;

• при испытаниях на ударный изгиб - по 6 образцам Менаже. 


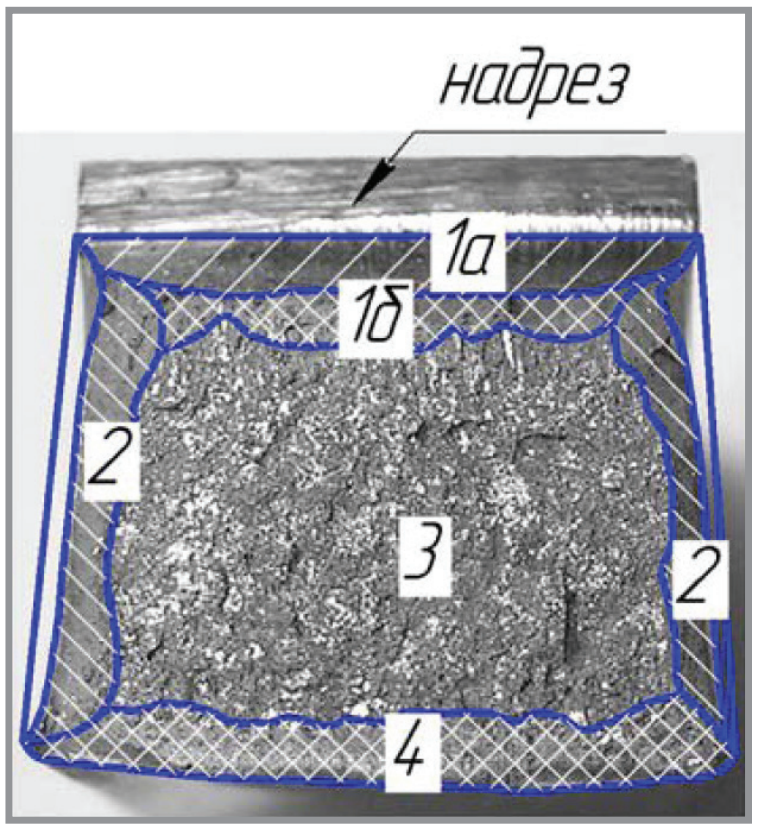

Рuc. 3. Структура поверхности излома стандартного образца типа I по ГОСТ 9454-78 [22]:

1 и и $1 б$ - зона зарождения и стабильного роста трещины, соответственно (сдвиговый механизм разрушения); 2 и 4 - зоны пластичного (сдвигового) разрушения; 3 - зона хрупкого (кристаллического) разрушения.

При репродукции увеличено в 5 раз

Исследования изломов стандартных образцов сечением 10х10 мм типа Менаже, испытанных на ударный изгиб, проводили по методу Ньюхауза и Горицкого (рис. 3) [22, 23].

На фотоснимках изломов при увеличении в 5 раз измеряли площади зон поверхности излома. Измерения проводили с помощью программы «КОМПАC 3D-V12». Относительную площадь хрупкой составляющей $\mathrm{X}_{\mathrm{p}}$ определяли по формуле

$$
X_{P}=\frac{F_{x p}}{F} \cdot 100(\%)
$$

где $\mathrm{F}_{\mathrm{xp}}$ - площадь зоны $3 ; \mathrm{F}=80 \mathrm{Mm}^{2}$ - общая площадь образца сечением 10х10 мм с надрезом.

Относительная площадь вязкой составляющей В соответственно равна:

$$
B=\left(100-X_{p}\right)(\%)
$$


Таблица 3

\section{Площади зон излома ударных образцов}

\begin{tabular}{|c|c|c|c|c|c|c|}
\hline \multirow{3}{*}{$\begin{array}{c}\text { Зоны } \\
\text { поверхности } \\
\text { излома }\end{array}$} & \multicolumn{2}{|c|}{ Гранулят без $\mathrm{TiO}_{2}$} & \multicolumn{2}{|c|}{$\begin{array}{c}\text { МХП, изготовленная } \\
\text { по существующей } \\
\text { технологии }\end{array}$} & \multicolumn{2}{|c|}{$\begin{array}{c}\text { МХП, изготовлен- } \\
\text { ная по предлагаемой } \\
\text { технологии }\end{array}$} \\
\hline & \multicolumn{2}{|c|}{ 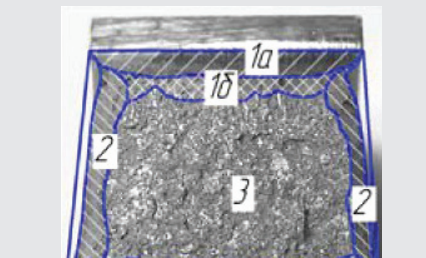 } & \multicolumn{2}{|c|}{ Comens 10} & $2 \times 10$ & 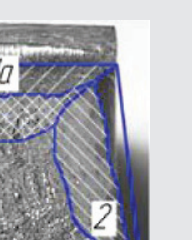 \\
\hline & $\begin{array}{c}\text { Площадь, } \\
\mathbf{M м}^{2}\end{array}$ & $\begin{array}{l}\text { Относи- } \\
\text { тельная } \\
\text { доля, \% }\end{array}$ & $\begin{array}{c}\text { Площадь, } \\
\text { мм }^{2}\end{array}$ & $\begin{array}{l}\text { Относи- } \\
\text { тельная } \\
\text { доля, \% }\end{array}$ & $\begin{array}{c}\text { Площадь, } \\
\text { мм }^{2}\end{array}$ & $\begin{array}{l}\text { Относи- } \\
\text { тельная } \\
\text { доля, \% }\end{array}$ \\
\hline Зона 3 (Fxp) & 53,54 & 67,0 & 44,3 & 55,4 & 35,20 & 44,0 \\
\hline $\begin{array}{l}\text { Суммарная } \\
\text { площадь вяз- } \\
\text { ких зон: 1a, } \\
16,2 \text { и } 4 \text { (Fв) }\end{array}$ & 26,46 & 33,0 & 35,7 & 44,6 & 64,8 & 56,0 \\
\hline
\end{tabular}

Результаты замера площадей вязкой и хрупкой составляющих в зоне излома металла шва с различными присадками представлены в табл. 3.

Полученные данные свидетельствуют о том, что применение МХП, изготовленной по новой технологии, обеспечивает увеличение площади вязкой составляющей в изломе ударного образца примерно на $12 \%$, а величину ударной вязкости - на $30 \%$.

Сравнительный химический анализ металла швов показал, что, несмотря на отсутствие титана в основном металле и электродной проволоке, при сварке с проволочной крошкой без добавок $\mathrm{TiO}_{2}$ (контрольный образец) и в корневом, и в облицовочном шве содержится 0,005\% титана (табл. 4).

Это свидетельствует о химическом взаимодействии сварочной ванны с флюсом АН-47, содержащим около $5,5 \% \mathrm{TiO}_{2}$. Содержание $\mathrm{Al}$ в шве зависит от концентрации $\mathrm{TiO}_{2}$ в сварочной ванне. Амфотерный 
таблица 4

\section{Результаты химического анализа металла швов}

\begin{tabular}{|c|c|c|c|c|c|c|c|c|c|}
\hline \multirow{2}{*}{$\begin{array}{c}\text { № } \\
\text { ПI/ா }\end{array}$} & \multirow{2}{*}{$\begin{array}{c}\text { Вариант } \\
\text { приготовле- } \\
\text { ния МХП }\end{array}$} & \multirow{2}{*}{$\begin{array}{c}\text { Зона } \\
\text { анализа }\end{array}$} & \multicolumn{6}{|c|}{ Содержание элементов в \% \% } & \multirow{2}{*}{$\begin{array}{c}\text { Расположение } \\
\text { исследованных зон }\end{array}$} \\
\hline & & & $\mathbf{T i}$ & Mn & $\mathbf{S i}$ & Al & C & $\mathbf{S}$ & \\
\hline 1 & $\begin{array}{l}\text { Без добавки } \\
\mathrm{TiO}_{2}\end{array}$ & $\begin{array}{l}\text { Корне- } \\
\text { вой шов }\end{array}$ & 0,005 & 0,73 & 0,63 & 0,03 & 0,088 & 0,015 & \\
\hline 2 & $\begin{array}{l}\text { Существую- } \\
\text { щая техноло- } \\
\text { гия добавка } \\
\mathrm{TiO}_{2} \text { в МХП } \\
\mathbf{0 , 4 \%} \text { (масс) }\end{array}$ & $\begin{array}{l}\text { Корне- } \\
\text { вой шов }\end{array}$ & 0,007 & 0,70 & 0,65 & 0,08 & 0,077 & 0,015 & \\
\hline 3 & $\begin{array}{l}\text { Новая техно- } \\
\text { логия добавка } \\
\mathrm{TiO}_{2} \text { в МХП } \\
0,4 \% \text { (масс) }\end{array}$ & $\begin{array}{l}\text { Корне- } \\
\text { вой шов }\end{array}$ & 0,010 & 0,64 & 0,61 & 0,08 & 0,080 & 0,007 & 2 \\
\hline 4 & $\begin{array}{l}\text { Без добавки } \\
\mathrm{TiO}_{2}\end{array}$ & $\begin{array}{c}\text { Облицо- } \\
\text { вочный } \\
\text { шов }\end{array}$ & 0,005 & 0,95 & 0,46 & 0,04 & 0,070 & 0,021 & \\
\hline 5 & $\begin{array}{l}\text { Существую- } \\
\text { щая техноло- } \\
\text { гия добавка } \\
\mathrm{TiO}_{2} \text { в МХП } \\
\mathbf{0 , 4 \%} \text { (масс) }\end{array}$ & $\begin{array}{c}\text { Облицо- } \\
\text { вочный } \\
\text { шов }\end{array}$ & 0,005 & 0,96 & 0,49 & 0,08 & 0,070 & 0,021 & \\
\hline 6 & $\begin{array}{l}\text { Новая техно- } \\
\text { логия добавка } \\
\mathrm{TiO}_{2} \text { в МХП } \\
0,4 \% \text { (масс) }\end{array}$ & $\begin{array}{c}\text { Облицо- } \\
\text { вочный } \\
\text { шов }\end{array}$ & 0,007 & 0,94 & 0,54 & 0,07 & 0,070 & 0,01 & \\
\hline
\end{tabular}

оксид $\mathrm{Al}_{2} \mathrm{O}_{3}$, средняя концентрация которого во флюсе около $11 \%$, при наличии в ванне кислотного диоксида титана переходит из флюса в сварочную ванну. При этом образуются центры кристаллизации в виде неметаллических включений наноразмерного порядка из оксидных комплексов $\mathrm{Al}_{2} \mathrm{O}_{3} \cdot \mathrm{TiO}_{2}$ в нитридо-титановой оболочке, как и $\alpha$-железо, имеющей объемно-центрированную кубическую кристаллическую решетку [13, 24]. Содержание серы, одного из самых вредных охрупчивающих элементов, в швах, сваренных с МХП, изготовленной по новой технологии, в 2 раза меньше, чем в изготовленной по старой. 


\section{Выводы}

1. Применение высокоэнергетической установки для приготовления металлохимической сварочной присадки с ускорением соударения смешиваемых частиц более $20 \mathrm{~g}$ обеспечивает 2-х кратное, по сравнению с существующей технологией, увеличение прочности сцепления и измельчение частиц модификатора до наноразмерного уровня.

2. Измельчение модифицирующих частиц и высокая прочность их сцепления с гранулятом обеспечивают формирование мелкозернистой структуры металла шва с высокими и стабильными прочностными показателями.

\section{УВАЖАЕМЫЕ КОЛЛЕГИ!}

ПРИ ИСПОЛЬЗОВАНИИ МАТЕРИАЛА ДАННОЙ СТАТЬИ

ПРОСИМ ДЕЛАТЬ БИБЛИОГРАФИЧЕСКУЮ ССЫЛКУ НА НЕЁ:

Болдырев А.М., Орлов А.С., Гущин Д.А. Новая технология получения гранулированного присадочного материала с наномодифицирующими добавками для дуговой сварки сталей // Нанотехнологии в строительстве. - 2016. - Том 8, № 6. - C. 124-143. - DOI: dx.doi.org/10.15828/2075-8545-2016-8-6-124-143.

\section{DeAR COlleagues!}

THE REFERENCE TO THIS PAPER HAS THE FOLLOWING CITATION FORMAT:

Boldyrev A.M., Orlov A.S., Guschin D.A. New technology for production of granular adding material with nanomodifying additives for steel arc welding. Nanotehnologii v stroitel'stve $=$ Nanotechnologies in Construction. 2016, Vol. 8, no. 6, pp. 124143. DOI: dx.doi.org/10.15828/2075-8545-2016-8-6-124-143. (In Russian). 


\section{Библиографический список:}

1. Патон Б.Е. Современные направления исследований и разработок в области сварки и прочности конструкций // Автоматическая сварка. - 2003. - №10/11. - С. 7-13.

2. Любовии Г. Предисловие редактора / Г. Любовиц // Разрушение: в 6 томах. Том 1. М. : Мир, 1973. -616 с.

3. Еремин К.И. Реестр зданий и сооружений 2007-2010 г.г. - М. - 2011. - 320 с.

4. Патон Б.Е. Современные направления повышения прочности и ресурса сварных конструкций / Б.Е. Патон // Автоматическая сварка. - 2000. - №9/10. - С. 3-9.

5. Нотт Дж.Ф. Основы механики разрушения / Дж. Ф. Нотт // Перевод с англ. Д.В. Лаптева [под ред. В.Г. Кудряшова]. - М.: Металлургия, 1978. - 256 с.

6. Иоффе А.Ф. Деформация и прочность кристаллов / А.Ф. Иоффе, М.В. Кирпичева, Н.А. Левитская // Журнал Русского физико-химического общества. - 1924. - Т. 56. C. $1489-1495$.

7. Петч H. Металлографические аспекты разрушения / Н. Петч // Разрушение: в 6 томах. Том 1. Микроскопические и макроскопические основы механики разрушения. М.: Мир, 1973. - 616 с.

8. Алов А.А. Модифицирование металла шва при сварке алюминия / А.А. Алов, Г.Б. Бобров // Сварочное производство. - 1959. - № 6. - С. 1-6.

9. Хренов К.К. Особенности модифицирования титаном сварных швов при автоматической сварке среднеуглеродистых сталей / К.К. Хренов, Л.А. Поздняк, Ю.А. Юзвенко, М.С. Самотрясов // Сварочное производство. - 1959. - № 6. - С. 6-8.

10. Болдырев А.М. Управление кристаллизацией металла при сварке плавлением / А.М. Болдырев, Э.Б. Дорофеев, Е.Г. Антонов // Сварочное производство. - 1974 № 6. - С. 35-37.

11. Коберник Н.В. Современные представления о модифицировании наплавленного металла и металла шва наноразмерными частицами (обзор) / Н.В. Коберник, Р.С. Михеев, А.С. Панкратов, А.А. Линник // Сварка и Диагностика - 2015. - № 5. - С. 13-18.

12. Болдырев А.M. Оценка термодинамических факторов взаимодействия металлохимической присадки со сварочной ванной // А.М. Болдырев, Д.А. Гущин, В.Д. Кузнецов, И.В. Смирнов / Научный вестник Воронежского ГАСУ. Строительство и архитектуpa. - Воронеж, 2014. - Вып. № 2 (34). - С. 24-33.

13. Головко В.В. Особенности распределения и роль неметаллических включений в металле шва при введении в сварочную ванну нанооксидов // В.В. Головко, А.М. Болдырев, Д.А. Гущин, С.К. Фомичев, В.Д. Кузнецов, И.В. Смирнов / Сварка и Диагностика. М. - 2015. - № 6. - С. 25-28.

14. Кузнецов В.Д. Структура и свойства металла сварного шва, модифицированного нанооксидами / В.Д. Кузнецов, Д.В. Степанов // Автоматическая сварка. - 2015. - № 11. C. 19-24.

15. Болдырев А.М. Проблемы микро- и наномодифицирования швов при сварке строительных металлоконструкций / А.М. Болдырев, В.В. Григораш // Нанотехнологии 
в строительстве. - 2011. - Toм 3, № 3. - C. 42-52. - URL: http://nanobuild.ru/ru_RU/ journal/Nanobuild_3_2011_RUS.pdf (дата обращения: 22.11.2016).

16. Способ электродуговой сварки [Текст] : Авт. свид. СССР №584996 :В 23 K 9/00. / А.М. Болдырев, Э.Б. Дорофеев, А.С. Петров, Т.И. Глазьева (СССР). № 2361777/25027; заявл. 17.04.76; опубл. 25.12.77. Бюл. № 47. 2 с.

17. Болдырев А.M. Влияние диоксида титана в составе металлохимической присадки на механические свойства металла шва стали 10ХCHД // А.М. Болдырев, В.Г. Гребенчук, Д.А. Гущин / Сварка и Диагностика. - М. -2014. - № 3. - С. 39-42.

18. Болдырев А.M. Исследование прочности сцепления частиц в модифицирующей присадке для сварки мостовых конструкций под флюсом / А.М. Болдырев, В.В. Григораш, Д.А. Гущин, В.Г. Гребенчук // Нанотехнологии в строительстве. - 2012. - Том 4, № 2. - C. 56-69.-URL: http://nanobuild.ru/ru_RU/journal/Nanobuild_2_2012_RUS. pdf (дата обращения: 22.11.2016).

19. Патент РФ 2574930 МПК8 В23К 35/40, В22F 1/02, В22F 9/04, В02C 17/08. Способ получения гранулированного присадочного материала для дуговой сварки / А.М. Болдырев, Д.А Гущин, И.В. Гребенчук. Заявитель и патентообладатель Федеральное государственное бюджетное образовательное учреждение высшего профессионального образования «Воронежский государственный архитектурно-строительный университет». - 2014119083/02, заявл. 12.05.2014, опубл. 10.02.2016, Бюл. № 4. -4 с.

20. Гущин Д.А. Получение металлохимической сварочной присадки с нанодисперсными частицами диоксида титана / А.М. Болдырев, В.Г. Гребенчук, Д.А. Гущин, А.Г. Ткачев, С.В. Блинов // Нанотехнологии в строительстве. - 2013. - Том 5, №6. - С. 5366. - URL: http://nanobuild.ru/ru_RU/journal/Nanobuild_6_2013_RUS.pdf (дата обращения 22.11.2016).

21. Салтыков С.A. Стереометрическая металлография. - М.: Металлургия, 1976. - 270 с.

22. Newhouse, D.L. Relationships Between Charpy Impact Energy, Fracture Appearance and Test Temperature in Alloy Steels / D.L. Newhouse // WELDING RESEARCH SUPPLEMENT. - 1963. - №3. - p. 105-114.

23. Горицкий В.М. Оценка сопротивления распространения трещины по результатам испытаний на ударную вязкость / В.М. Горицкий, Д.П. Хромов // «Заводская лаборатория». -1984 . - № 7. - С. 70-73.

24. Головко В.В. Влияние неметаллических включений на формирование структуры металла сварных швов высокопрочных низколегированных сталей / В.В. Головко, И.К. Походня // Автоматическая сварка. - 2013. - № 6. - С. 3-11. 